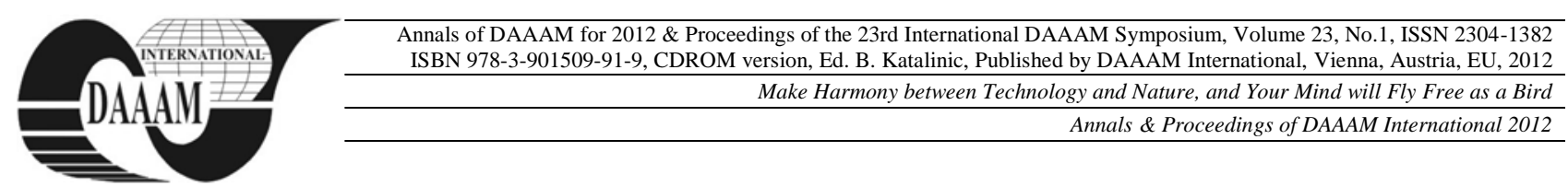

\title{
INSPECTION PROCEDURE OF TANKS AND VOID SPACES
}

\author{
BOSTINA, A[urel]; BOSTINA, A[lina]; ACOMI, N[icoleta] \& DOINEA, G[eorgiana] R[odica]
}

\begin{abstract}
This paper aims to present details of the processes and techniques associated with performing an onboard inspection and enhance structural knowledge so that the maintenance and repair activities are better structured and informed.

Guidance is given on structural inspections and the common defects encountered.

All defects that affect the structural efficiency or the safety of the ship are to be reported to classification society at the earliest opportunity.

To identify where a defect is likely to occur you will need to take into account all of the factors. The structural areas to be inspected shall include cargo spaces, ballast tanks, the main deck, fore and aft end structure, engine room and machinery spaces, and the accommodation areas. Each of these areas may have particular defects that occur only in that area.
\end{abstract}

Keywords: defects, corrosion, deformation, inspection process

\section{INTRODUCTION}

The purpose of this study is to provide a useful guide and training of performing onboard ships inspections of enclosed spaces such ballast tanks, void spaces, cargo holds, etc. In this guide is explained and defined the terms and factors involved for a better comprehension of processes and techniques. The aim is also to enhance structural knowledge so that the maintenance and repair activities are better structured and informed.

It is natural that ships deteriorate physically over time, but if unchecked, this deterioration can lead to serious structural defects and ultimately to the loss of the ship. To avoid both loss of life or loss of revenue from periods when the ship is forced to be off hire, effective maintenance is essential. Wear and tear defects, in themselves, are not dangerous, but if undetected and/or left without rectification, then serious consequences could ensue.

All defects must be fully assessed and the appropriate action taken. If there is any query or doubt regarding the efficiency of the structure and or protective coatings, a surveyor should be called to attend. Some guidance on defects is provided in the ship specific units of this training. [5]

General defects that constitute wear and tear are:

- corrosion

- deformation

- fractures

\section{CORROSION}

Corrosion, otherwise known as material wastage, is often the cause of fractures and deformation, particularly where the diminution in steel thickness is great enough to compromise the strength of the structural member. Corrosion in general will lead to the highest maintenance and rectification costs throughout the life of a ship. Corrosion, if left unchecked, can lead to the contamination of cargo and/or fuel oil, pollution, and ultimately the loss of the ship.

The most effective way to prevent costly steel renewals is to apply and maintain quality protective coatings in a satisfactory condition, particularly in ballast tanks where corrosion can occur at a fast rate. Details and examples of material wastage or corrosion are provided later in this Unit. Typical corrosion terms include:

\section{General Corrosion}

The damp and salty atmosphere at sea will react with uncoated steel to form rust.

\section{Aqueous corrosion}

An electrochemical reaction between a metal and its aqueous environmen.

Galvanic

This is the preferential corrosion of one metal over another.

\section{Seawater corrosion}

Salt water is more corrosive than fresh water - semiprotective scale is less well formed.

Erosion

This is a result of the scouring action of water, other fluid, or flow borne particles. [3],[4].

\section{DEFORMATION}

A change in shape or disfigurement of a structural area is commonly referred to as deformation and is caused in one of the following three ways:

- by an applied load that results in an elastic deformation of the structure, with the structure returning to its original state after the load is removed

- a plastic deformation caused by the application of a stress that is greater than the yield stress, or

- plastic buckling where a small increase in stress causes a large increase in deformation. 
The applied force may be dynamic (wave loading), static (still water bending - cargo weight), or a shear force and may be applied in plane - a compressive force, or out of plane - a bending force. The tendency of a deformed structure is that it will lose its efficiency. Note that repeated elastic deformation can lead to fatigue failure.

When a deformation is observed in the ships hull or a tank boundary, it is important to also check the internal structure as this will often be deformed. Buckled structure will tend to transmit force less efficiently than the original and may be prone to complete structural failure. However some ships have suffered spectacular incidents and remained intact.

If we consider structural panels, such as those constituting the side shell, these are constructed of the panel plating and associated stiffeners. Deformation of the plating and stiffeners can occur independently but will often occur together. [3],[4].

\section{FRACTURES}

A fracture is the result of the propagation of a crack through the thickness of the steel plate or stiffener. In most cases, fractures are found at locations where stress concentrations occur. Through experience we know that areas of stress concentrations include weld defects, flaws, and locations where lifting fittings were temporarily fitted and not properly removed during the construction of the ship. Additionally, fractures can also occur in way of notches, openings or slots.

If fractures have occurred under repeated stresses that are below the yielding stress, they are called fatigue fractures. In addition to the cyclic stresses caused by wave forces, fatigue fractures are also caused by vibration forces. Such forces are typically experienced in the aft end of the ship and are due to the effects of the main engine and propeller.

Fractures initiating in way of weld defects, commonly appear at the beginning or end of a run of welding, or rounding corners at the end of a stiffener, or at an intersection. Special attention should be paid to welding at toes of brackets, cut-outs and intersections of welds. Fractures may also be initiated by undercutting the weld in way of stress concentrations.

Although now less common, intermittent welding may cause problems because of the introduction of stress concentrations located at the ends of each length of weld. Fractures, particularly fatigue fractures due to repeated stresses, may lead to serious damage. For instance, a fatigue fracture in a structure adjacent to the shell plating may propagate into the shell plating itself, and affect the watertight integrity of the hull. Similarly, fractures initiating at the hatch corners may propagate into or extend across the main deck, resulting in a catastrophic failure. [3],[4].

Any fracture, if undetected or left to propagate naturally, can have very serious consequences. Although fractures are inherently common in some ships' structures they should be repaired at the earliest opportunity. [1]

\section{INSPECTION PROCESS \& TECHNIQUE}

It is utmost important to be used personal safety equipment and adhere to safety practices in force. [5]

\section{Assessing overall condition}

On entry into a space you can readily assess its overall condition by considering the following:

- ladders and access ways

- overall impressions of protective coatings

- indications of areas with heavy scaling

- fallen scale

A quick assessment of the overall condition of a tank or space will generally allow you to gauge the degree of rigour required for inspection.

Ladders and access ways are often the first part of a tank's protective coating to deteriorate. An overall impression of the coatings will allow you to gauge the general state of the tank in regard to corrosion. Re-coated areas are easy to spot, as it is very difficult to achieve the same level of finish compared to coatings applied at new construction. Areas that have been touched up by hand over the top of scale should be carefully inspected, as the corrosion can continue behind the coating. [5]

\section{Lighting}

Adequate lighting is essential for inspection work and for the detection of defects. Shadows can indicate areas where there is deformation and can also help to pinpoint cracks. Tanks with different types of coating require different levels of light for a successful inspection. For example, coal tar, epoxy coatings are dark in colour and absorb light and so require more illumination than tanks with light coloured coatings. Light coloured coatings are also beneficial as they contrast well with rust. This allows for easier identification of general corrosion, and the local corrosion brought on by the breakdown of the coating in way of a crack.. [5]

\section{Cleaning of mud and oil sludge from tanks}

Mud and oil sludge in tanks can hide serious defects and also encourage the development of pitting in horizontal surfaces. Before inspection, excess mud that has accumulated due to ballasting operations should be removed, so that any bottom shell pitting can be detected.

\section{Environmental pre-disposing factors}

Some areas of the ship will be more prone to certain defects than others such as:

- ballast tanks adjacent to the engine room bulkhead

- ballast tanks adjacent to heated oil fuel or cargo tanks

- areas where there is an increased level of vibration

- side shell between light and loaded draughts and in way of tug contact points

- $\quad$ side shell forward after heavy weather [5]

\section{Identifying structurally significant items (SSI’s)}

Structurally significant items, (SSI's), are hull structural items that are considered critical because of the consequence of failure and/or due to the increased risk of failure. Often they are areas that have an increased risk of 
failure from fatigue fracture. SSI's may be evident because of global loading, detailed design which causes high stress concentrations, or both of these factors.

Before entering a space you should have an idea of the expected types of defects and their likely locations, and you should be aware of those items which are structurally significant. These areas will include all external boundary plating such as the outer bottom, primary and secondary strength members such as longitudinal and transverse bulkheads, longitudinal girders etc. [3]

\section{Identifying areas at risk of defect occurrence}

To identify where a defect is likely to occur you will need to take into account all of the factors just mentioned. The structural areas to be inspected shall include cargo spaces, ballast tanks, the main deck, fore and aft end structure, engine room and machinery spaces, and the accommodation areas. Each of these areas may have particular defects that occur only in that area. However some common defects may occur in each of these structural areas.

\section{Identifying defects:}

\section{a. Corrosion}

- corrosion is generally identified due to the discoloration of a surface or by the presence of scale

- general corrosion may be extensive and severe but may only be indicated by a light scale

- hammering a structure may give an indication of remaining material. However to gain a true picture, ultrasonic thickness gauges should be used

\section{b. Fractures}

- fractures maybe indicated as a leak in a bulkhead, i.e. rust/oil streaks

- fractures are often indicated by a local breakdown of the protective coating

- fractures contrast well in tanks with light coloured coatings

- where a fracture is suspected, a number of non destructive examination techniques can determine the extent of the defect

\section{c. Deformations}

- deformations may not be readily evident if present over a large area

- shining a torch beam in parallel over a flat plane structure will indicate deformation

- a length of string can be used to measure the extent of deformation

\section{Repairs}

Classification societies adopt a set of repair standards that have been developed from experience and are generally accepted throughout the industry. In some instances, a defect will be found that will require the attention of a surveyor who, in turn, may recommend a particular repair. [2]

\section{TANK TESTING}

Tank testing is used to confirm the strength and watertight integrity of tanks and identify any leaks. Tanks that require to be tested include double bottom compartments, ballast tanks, peak tanks, cargo tanks and all other tanks that form an integral part of the ship's structure, such those used for the carriage of fresh water, lubricating oil and fuel oil. Special arrangements exist for the testing of cargo tanks on ships designed for the carriage of liquefied gases.

To confirm that the structure of the tank remains satisfactory, it is necessary to perform the test with a head of liquid that is equivalent to the maximum head that the tank will experience in service. Normally, testing consists of the tank in question being filled such that the air pipes are overflowing. Where the liquid being used presents a risk of pollution, it is sufficient to fill the tank to its highest point, i.e. the crown of the tank.

All boundaries of the tank should be inspected whilst under pressure but it is not necessary to inspect the boundary from both sides. i.e. If two adjacent tanks are pressed up, the common boundary need only be inspected once. By careful selection for test of the tanks that are pressed up, it is possible to inspect all boundaries without filling every tank.

The plane surface of the bulkhead should be checked for deformation by shining a torch across the surface. Any deformation found should also be checked when the boundary is not under pressure. This will allow confirming if the deformation is elastic or plastic. Repeated elastic deformation may lead to fatigue fractures. Any deformation or leaks should be reported to Classification Society.

Any leak discovered during a test must be recorded and, where possible, the cause identified. If the cause is corrosion, steps should be taken to determine its extent.

Recording the boundaries inspected may be done by using a copy of the tank capacity plan or general arrangement. It is possible to record the progress of tank testing throughout ballasting and cargo operations over the 5-year period. [1], [2].

\section{PROTECTIVE COATING CONDITION}

The inspection, assessment and maintenance of protective coatings in water ballast tanks is important. In the case of oil and chemical tankers, tanks where protective coatings are allowed to degrade to a FAIR condition will be examined at each Annual Survey. In the case of all other ship types, tanks where protective coatings are allowed to degrade to a POOR condition will be examined at each Annual Survey. [1], [2].

The condition of the protective coating in all ballast tanks must be reported as and when the tank is inspected under the scheme assessed as either: GOOD, FAIR or POOR.

A coating assessed as being in GOOD condition will have only minor spot rusting affecting not more than $20 \%$ of areas under consideration. e.g. On a deck transverse, side transverse, on the total area of plating 
and stiffeners on the longitudinal structure between these components, etc.

A coating assessed as being in FAIR condition will have local breakdown at edges of stiffeners and weld connections and/or light rusting over $20 \%$ or more of areas under consideration.

A coating assessed as being in $P O O R$ condition will have a general breakdown of coating over $20 \%$ or more of areas or hard scale at $10 \%$ or more of areas under consideration. [1], [2].

\section{TYPICAL STRUCTURAL DEFECTS}

Many defects are considered to be common and can be found on whichever ship type is being examined. Ballast tanks on all ship types will experience typical problems. These being: fractures and deformations, corrosion, fatigue fractures.

\section{Deformations}

Deformation of structure is caused by in-plane load, out-of-plane load or combined loads. Often, deformation is described as being either local or global in nature. Local deformation will normally be limited to one panel including stiffeners, while global deformation will affect a larger structural area, including plating, beams, frames, girders and floors, etc.

If a large deformation is caused due to a small increase of the load, the process is called buckling. Impact loads or contact, and inadvertent overloading, often cause deformations. Damage due to bottom slamming and wave impact forces are, in general, found in the forward part of the hull, although stern seas (pooping) have resulted in damage in way of the after part of the hull. In the case of damage due to contact with other objects, you should pay special attention to the fact that although damage to the shell plating may look small from the outboard side, in many cases the internal members are heavily damaged.

Permanent buckling may arise as a result of overloading, overall reduction in thickness due to corrosion, or contact damage.

Elastic buckling will not be directly obvious but may be detected by coating damage, stress lines or shedding of scale. Buckling damage is often found in webs of web frames or floors. In many cases this is due to corrosion of webs and/or floors, too wide a spacing of stiffeners, or wrongly positioned lightening holes, manholes or slots in webs and/or floors. It should be noted that inadvertent overloading might cause significant damage. In general, however, major causes of damage are associated with excessive diminution of the steel thickness and contact damage.

\section{Material wastage}

In addition to being familiar with typical structural defects likely to be encountered during an inspection, you need to be aware of the various forms and possible location of material wastage, or corrosion, that may occur to the decks, cargo spaces, ballast tanks and other structural areas.
General corrosion appears as a non- protective, friable rust which can occur uniformly on hold or tank internal surfaces that are uncoated. The rust scale continually breaks off, exposing fresh metal to corrosive attack. Thickness diminution cannot usually be judged visually until excessive diminution has occurred. In coated tanks and holds, corrosion takes place as the coatings start to break down. The picture shows a typical example of knifing where the coating has broken down on the edge of a flange. Failure to remove mill scale during construction of the ship can accelerate corrosion experienced in service. Severe general corrosion in all types of ships, usually characterised by heavy scale accumulation, can lead to extensive and costly steel renewals.

Grooving corrosion is often found in or beside welds, especially in the heat-affected zone. A galvanic current, generated from the difference of the metallographic structure between the heat-affected zone and base metal, causes the corrosion. Coating of the welds is generally less effective compared to other areas, due to rough surfaces which exacerbate the corrosion. The grooving corrosion may lead to stress concentrations and further accelerate the corrosion. Grooving corrosion may be found in the base material where coating has been scratched or the metal itself has been mechanically damaged.

Pitting corrosion is often found in the bottom plating of ballast tanks. If a place is liable to have corrosion due to local breakdown of coating, pitting corrosion starts. Once started, it is exacerbated by a galvanic current between the pit and other metal.

Erosion, which is caused by the effect of liquid and abrasion, caused by mechanical effect, may also be responsible for material wastage. [3], [4].

\section{CONCLUSION}

A proper detailed inspection and techniques as described, identifying structural defects and deteriorations, areas at risk of defect occurrence, combined with an overall assessment of condition and a correct maintenance will increase safety and prevent huge costly steel renewals, loss of revenue, early fatigue or even loss of ship.

\section{REFERENCES}

[1] *** Bureau Veritas - Marine Division General Condition Guidance for Ultra Large Container Ships - October 2010

[2] *** Bureau Veritas - Shipbuilding and Repair Quality standard 1996 (revised Oct 2010)

[3] *** Bureau Veritas - VeriSTAR Hull - Complete Ship Model

[4] *** Det Norske Veritas - Hull Inspection Course 2007

[5] *** Personal Experience of authors performing shipboard duties activities, training and reserches on board vessels (authors are experts in the field) 